\section{An unusual case of recurrent hepatocellular carcinoma presenting as an indeterminate right intrahepatic duct stricture}

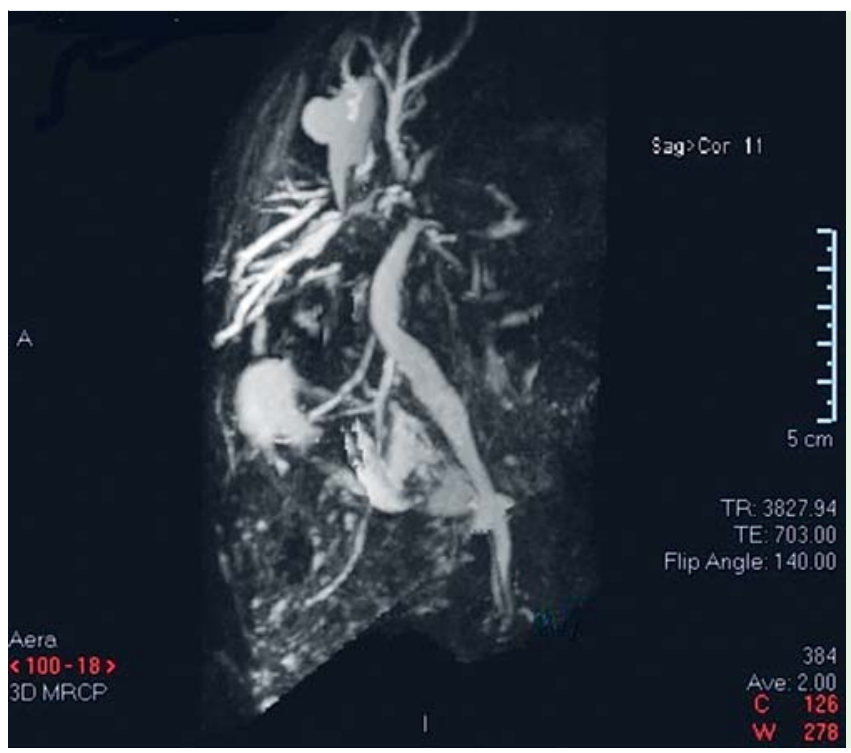

Fig. 1 Magnetic resonance cholangiopancreatography (MRCP) showing non-visualization of the central right intrahepatic duct and a focal defect in the left intrahepatic duct.

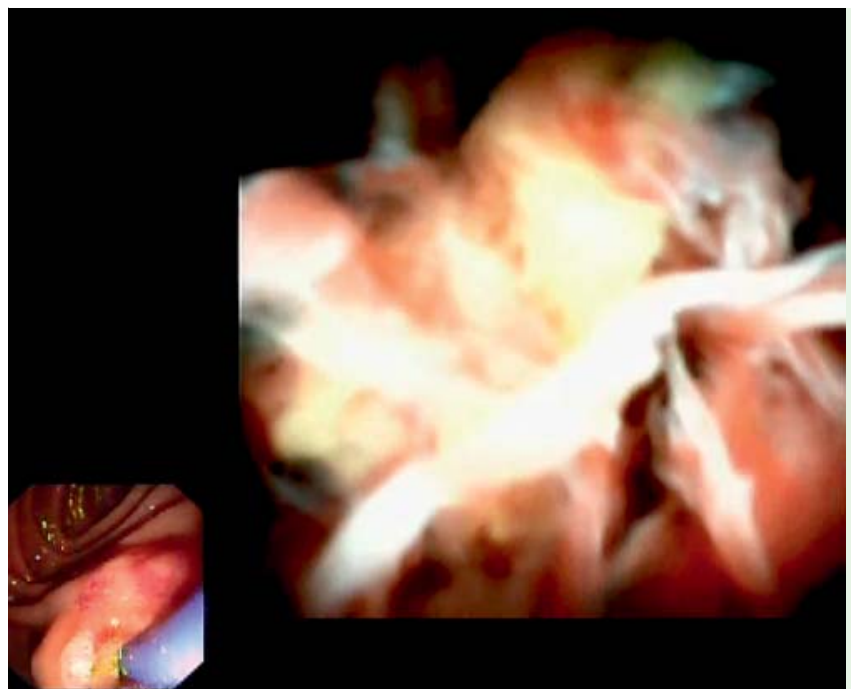

A 46-year-old man with segment 8 hepatocellular carcinoma (HCC) from hepatitis C-related, Child-Pugh class A cirrhosis underwent successful hepatic resection. This was complicated by a postoperative bilioma that was treated by percutaneous drainage. He presented again 6 months later with abdominal pain and cholestasis. Computed tomography (CT) of the liver showed no tumor recurrence. Magnetic resonance imaging (MRI) showed postcholecystectomy status, a mildly dilated common bile duct, non-visualization of the central right intrahepatic duct, a focal defect in the left intrahepatic duct, and proximal dilatation of both intrahepatic ducts ( Fig. 1). Cholangioscopy using the SpyGlass DS Direct Visualization System (Boston Scientific, Natick, Massachusetts, USA) was performed. Blood clots were visualized in the left intrahepatic duct. A friable mass was visualized in the right intrahepatic duct ( $\bullet$ Fig. 2) and was biopsied ( $\bullet$ Video 1). Bilateral stenting was performed. Histology revealed recurrent HCC ( $\bullet$ Fig. 3).

HCC recurrence tends to present as a mass, so patients routinely undergo sur-

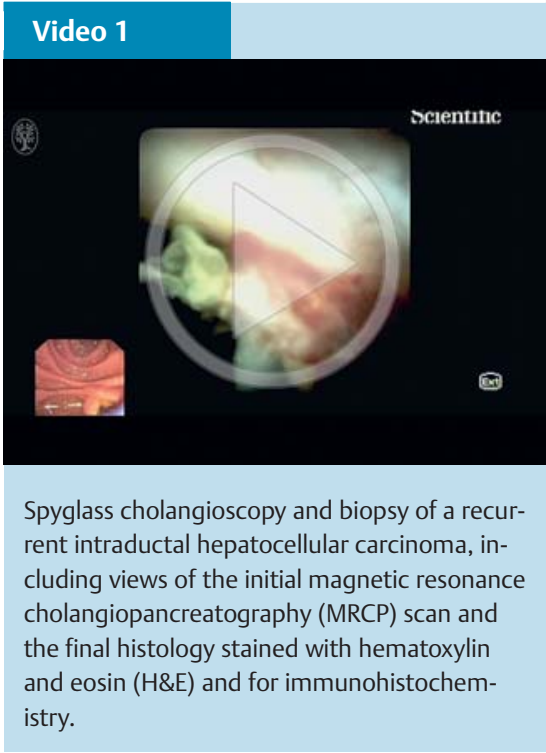

veillance CT or MRI scans at scheduled intervals [1]. Uncommonly intraluminal biliary obstruction may arise postoperatively because of hemobilia, migration of tumor debris, or a tumor mass with continuous growth along the biliary tree [2]. In this case, the only positive finding was the MRI scan that demonstrated an indeterminate stricture with no mass.

The first-generation Spyglass cholangioscopy system, which uses a fiber-optic probe, has been shown to be useful in determining the nature of indeterminate biliary strictures [3]. A systemic review demonstrated that the pooled sensitivity and specificity of cholangioscopy with targeted biopsies for the detection of cholangiocarcinoma were $66.2 \%$ and $97.0 \%$, respectively [4]. The second-generation digital Spyglass system has much better cholangioscopic image resolution, thereby facilitating endoscopic diagnosis and targeted biopsies. In this case, it was used to diagnose recurrent HCC with a rare presentation of isolated intrahepatic bile duct stricture with no associated liver parenchymal lesion.

Endoscopy_UCTN_Code_CCL_1AZ_2AC

Competing interests: None 


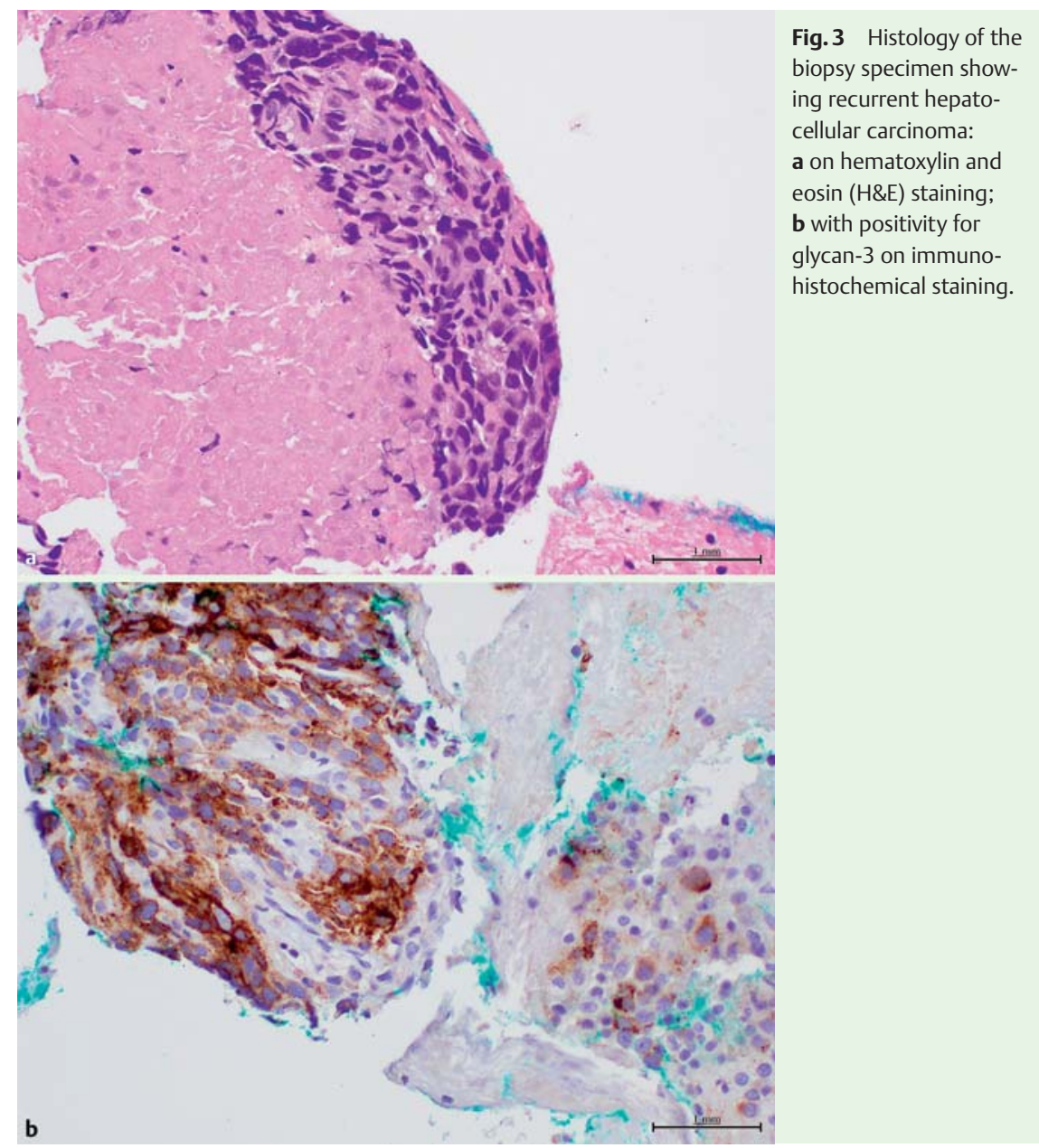

\section{Tiing Leong Ang ${ }^{1}$, Andrew Boon Eu Kwek', Wee Teng Poh ${ }^{2}$}

${ }^{1}$ Department of Gastroenterology and Hepatology, Changi General Hospital, Singapore

2 Department of Laboratory Medicine, Changi General Hospital, Singapore

\section{References}

1 Hatzaras I, Bischof DA, Fahy B et al. Treatment options and surveillance strategies after therapy for hepatocellular carcinoma. Ann Surg Oncol 2014; 21: 758 - 766

2 Xin KY, Yee LS, Yong TT et al. Obstructive jaundice due to intraductal tumour thrombus in recurrent hepatocellular carcinoma: what is the optimal therapeutic approach? Hepatogastroenterology 2014; 61: $1863-$ 1866

3 Chen YK, Parsi MA, Binmoeller KF et al. Single-operator cholangioscopy in patients requiring evaluation of bile duct disease or therapy of biliary stones (with videos). Gastrointest Endosc 2011; 74: 805-814

4 Navaneethan $U$, Hasan MK, Lourdusamy V et al. Single-operator cholangioscopy and targeted biopsies in the diagnosis of indeterminate biliary strictures: a systematic review. Gastrointest Endosc 2015; 82: 608-614

\section{Bibliography}

Dol http://dx.doi.org/

10.1055/s-0042-104280

Endoscopy 2016; 48: E121-E122

(c) Georg Thieme Verlag KG

Stuttgart · New York

ISSN 0013-726X

\section{Corresponding author \\ Tiing Leong Ang, MD}

Department of Gastroenterology and Hepatology Changi General Hospital

2 Simei Street 3

Singapore 529889

Singapore

tiing_leong_ang@cgh.com.sg 